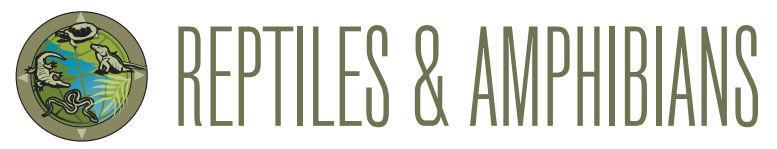

\title{
A Common Bronze-backed Treesnake, Dendrelaphis tristis (Daudin 1803), Laying Eggs in a Fallen Baya Weaver's, Ploceus philippinus (Linnaeus 1766), Nest in Odisha, India
}

\author{
Sandipt Maharana ${ }^{1}$, Swarup Fullonton ${ }^{2}$, Shreya Pandey ${ }^{2}$, and Aurobindo Samal ${ }^{3}$ \\ ${ }^{1}$ Wildlife \& Biodiversity Conservation (WBC), Talcher, Angul, Odisha-759100, India (sandpit.maharana2@gmail.com) \\ ${ }^{2}$ Amity Institute of Forestry and Wildlife, Amity University, Noida, Uttar Pradesh-201301, India \\ (fullontonswarup@gmail.com, shreyapandey.2244@gmail.com [corresponding author]) \\ ${ }^{3}$ Earth Crusaders Organisation (ECO), Bhubaneswar, Odisha-751019, India (aurobindo.cse@gmail.com)
}

$\mathrm{T}$ he Common Bronze-backed Treesnake (Dendrelaphis tristis) is an arboreal colubrid that ranges across southern Asia from Pakistan in the west to Myanmar in the east and from northern India, Nepal, and Bhutan in the north south through most of India to Sri Lanka (Joshi et al. 2019; Uetz et al. 2021). Herein we document an instance of the Common Bronze-backed Treesnake laying eggs in an abandoned fallen nest of a Baya Weaver (Ploceus philippinus).

At about $1400 \mathrm{~h}$ on 24 August 2020, after receiving a snake rescue call from Talcher, Odisha, India $\left(21.142586^{\circ} \mathrm{N}\right.$, $85.198462^{\circ} \mathrm{E}$ ), we encountered a female D. tristis in a fallen Baya Weaver's nest. The snake appeared to be guarding three eggs (Fig. 1). Local residents were cautious and unaware that the snake was not venomous. Our team assured them that the snake was harmless and would leave without causing any problems. We took photographs of the snake in her nest without disturbing it.

Female D. tristis lay eggs "in a tree hole or old bird nest" (R. Whitaker in Singh 2020). However, to the best of our knowledge, this is the first record of a Common Bronzebacked Treesnake laying eggs in a Baya Weaver's nest.

\section{Acknowledgements}

We thank Team Wildlife and Biodiversity Conservation for promoting snake conservation through social awareness campaigns. We also thank the Earth Crusaders Organisation for literature and helpful comments on a draft of this manuscript.
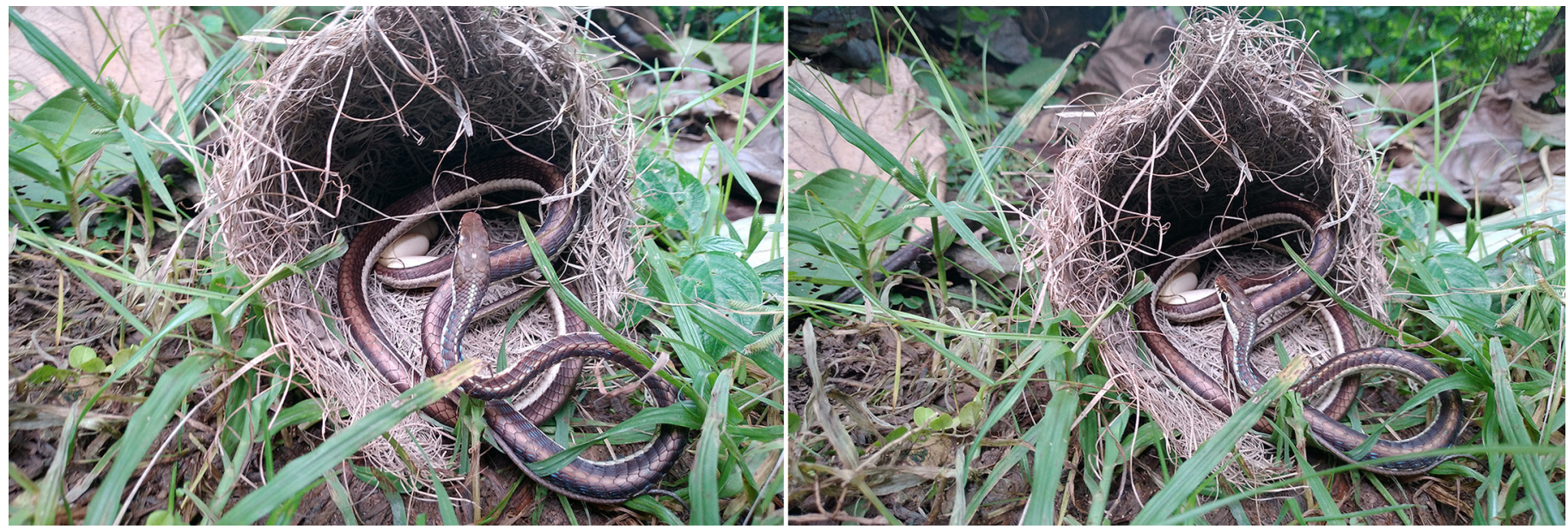

Fig. 1. A female Common Bronze-backed Treesnake (Dendrelaphis tristis) appears to be "guarding" her eggs in a fallen abandoned nest of a Baya Weaver (Ploceus philippinus). Photographs by Sandipt Maharana. 


\section{Literature Cited}

Joshi, R., A. Singh, and K. Puri. 2019. The northernmost record of the colubrid snake Dendrelaphis tristis (Daudin, 1803) (Reptilia: Squamata: Serpentes) in India (Rajaji Tiger Reserve). Herpetology Notes 12: 305-308.
Singh, V.J. 2020. Wildbuzz: Snake with a white bindi. Hindustan Times, 1 August 2020. <https://www.hindustantimes.com/chandigarh/wildbuzz-snake-with-awhite-bindi/story-sgQ7shOQ0pFAkqahFYAxVM.html>.

Uetz, P., P. Freed, R. Aguilar, and J. Hošek (eds.). 2021. The Reptile Database. $<$ http://www.reptile-database.org>. 